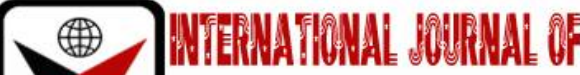

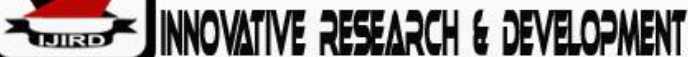

ISSN 2278-0211 (Online)

\section{Test Anxiety and Academic Achievement among Undergraduate Students in College of Education, Agbor, Delta State, Nigeria}

\begin{tabular}{|c|}
\hline Duke Ogochukwu Okobia \\
Lecturer, Department of Educational Psychology, \\
College of Education, Agbor, Delta State, Nigeria \\
John Ossai Oji \\
Lecturer, Department of Educational Psychology, \\
College of Education, Agbor, Delta State, Nigeria
\end{tabular}

\begin{abstract}
:
This study was designed to investigate test anxiety and academic achievement among undergraduate students in College of Education, Agbor, Nigeria. The design of the study was ex-postfacto and correlation designs. 260 final year undergraduate students who were available after one of their education examinations participated in the study. Test anxiety data were collected from the students, using Sarason (1978) test anxiety seale. However, 247 students out of the 260 students filled the test anxiety questionnaire correctly. This sample comprised 119 males and 128 females. Each student's final year cumulative grade point average (CGPA) was collected from the degree office of the college. The collected data were coded and analyzed, using regression and t-test statistics. Regression analysis revealed that there was a negative relationship between students' test anxiety scores and their academic performance (CGPA)(F1, 247=7.544; Beta= $0.173 ; P<0.05)$. A t-test analysis showed that there was no significant difference between the test anxiety scores of male and female undergraduate students ( $t$-Calculated $=1.065, d f=245 ; P>0.05)$. Further $t$-test analysis indicated that there was no significant difference in the academic achievement (CGPA) of male and female undergraduate students ( $t$-calculated $=0.337 ; d f=245 ; P>0.05$ ). It was recommended among others that the college authority should create test anxiety awareness in the college and provide learning environment that promotes tolerable level of test anxiety that will stimulate students to learn well and keep on learning.
\end{abstract}

Keywords: Test anxiety, academic performance, cumulative grade points average, undergraduate students

\section{Introduction}

Education remains the heart beat of any nation aspiring to greatness. It is as a result of this fact that each country or nation lays much premium on the education of its citizens. It is equally true that evaluation or examination plays vital role in ascertaining the standard of any nation's education system. The evaluation of education system all over the world rests on testing which helps to ascertain the skills the recipients exposed to the education system have acquired over the years. As education has been seen to occupy a central place in the development of nations, Nigeria inclusive, it therefore becomes necessary to investigate such factors which may negatively affect the performance of students exposed to it. It is such variable as students' test anxiety that this study is set to examine.

Generally, anxiety is a psychological and physiological state that encompasses somatic, emotional, cognitive and behaviour dimensions (Seligiman, Walker and Rosenhan (2008). It is a phenomenon that sets a body in a state of disequilibrium if not properly managed. Ramalingan (2006) sees anxiety as an 'emotional state arising in a situation of worry, nervousness and manifested in expectation for unfavourable events'. He goes onto highlight that anxiety is 'the physiological and psychological reaction to an expected danger, whether such danger exists or imagined'. From the above, it can easily be understood that everyone at one time or the other experiences anxiety. How each individual handles stressful situation depends on the intensity of the stressor and his capability to cope with such threaten event. A heighten level of anxiety inhibits individual's mental and physical health. Such elevated level of anxiety, has negative results on person's social, familial, occupational and educational performance (Zahrakar, 2008; Oluoch, Aloka and Odongo, 2018).

Anxiety responses have been classified into four components. (Barlow, 2002; Passer, Smith, Holt, Bremner, Sutherland and Vliek, 2009). These are;

- A subjective emotional component which comprises feeling of tension and apprehension.

- A cognitive component consisting of worrisome thoughts and a sense of inability to cope. 
- A physical component which involves responses as increase heart rate and blood pressure, tension, rapid breathing, nausa, dry mouth, diarrhea and frequent urination.

- Behavioural component which encompasses such responses as avoidance of certain situations and impaired task performance. As can be seen from the above description of anxiety, one is expected to experience one form of anxiety or the other as one interacts with one's environment characterized by complex choices and highly competitive situations. Anxiety therefore, is a normal reaction to a stressor that may help individuals to deal with a demanding situation by prompting them to cope with it. Anxiety becomes disorder when it is excessive in which case the body mechanism meant to regulate reaction to stressor has been overshadowed by forces generated by the stressor.

When anxiety is related to performance on a test or testing situations, it is termed test anxiety. Test anxiety is the phenomenological, physiological and behavioral reactions that accompany testing situations (Zeidner, 2007). It is that feeling of uneasiness, apprehension or nervousness by a testee that he or she may likely perform poorly in examination. A test anxious student may experience all or some of the following symptoms of poor self-worth, academically emptiness, fear of embarrassment by a teacher, sweating, headaches, fidgeting, nausea, dizziness, abnormal heartbeats, associating school performance with personal worth and inability to have a refreshing level of sleep due to irrelevant thoughts (Passer etal., 2009).The extent to which students experience any or all of the above characteristics varies from individual to individual as an optimal level of arousal is required to best complete a task such as performance in examination.But test anxiety becomes problematic when the level of arousal supersedes optimal level, thus resulting in a decline in academic performance. Test anxiety has been classified into two major dimensions which are the worry and emotionality. (Cassady and Johnson (2002). The worry aspect is concerned with the negative thoughts and concerns that the testee has before, during and after testing situations. These negative thoughts and concerns are what inhibit students' abilityto concentrate, assimilate, consolidate and decode learning materials, thus leading to poor academic performance. The emotionality dimension is the heightened physiological symptoms emanating from arousal of the autonomic nervous system and associated responses (Karate, Alci and Aydin (2013). Such physiological symptoms include; increase galvanic skin responses and heart rate, dizziness, nausea and feeling of panic. Cassady and Johnson (2002) reported that participants having average level of emotionality performed better than those having high emotionality. However, researchers have demonstrated that the cognitive aspect (worry component) of test anxiety has more significant influence on test performances than emotionality component (Williams, 1991; Bandalos Yates and Thomdike, 1995).

A number of studies have found that test anxiety has debilitating effect on academic performance (Zeidner, 2007; Dordinejad, Hakim, Ashouri, Dehghan, Zeinali, Daghighi and Bahrami, 2011). Chapel, Blanding, Silverstein, Takahashi, Newman, Gubi and Mccann (2005) designed a study to investigate the relationship between test anxiety and academic performance among graduate and undergraduates students. They found negative significant relationship between test anxiety and grade point average (GPA) in both groups. In a study conducted by Eysenck (2009), it was found that anxious students exhibited more difficulty in avoiding distractions and spent more time to shift their attention from one task to the next than their less anxious mates. This finding supports cognitive interference model for test anxiety which states that people that experience high levels of test anxiety significantly perform poorly as a result of their inability to suppress competing thoughts (Sarason, 1984). It is either high level test anxiety individuals are concentrating attention on irrelevant cues for the test or are incapable of restricting the range of cues, thus allowing competing thoughts to enter conscious level and interfere with performance. When attention and concentration are crippled, then, working memory will be impaired, resulting in poor academic performance. In a similar study, Nedeem, Ali, Magbool and Zaida (2012) found that test anxiety had significant negative correlation on academic performance of students having different mental abilities. Alemu and Feyssa (2020) in a study to explore the relationship between test anxiety and academic achievement of grade ten students in Aromia Regional State in Ethiopia, found that there was a significant negative relationship between test anxiety and students achievement Acromia. From the above findings, it is clear that test anxiety has deleterious effects on students academic performance and that there is need for teachers to explore means of helping students to utilize their full potentials with a view to achieving optimal performance.

In spites of numerous studies reporting inverse relationship between test anxiety and academic performance, some other studies have reported contrary results. Owolabi and Etuk-Iren (2014) for instance found that levels of anxiety had no significant effect on mathematics achievement among college students. They however found that those with medium level of anxiety had highest mean score while the highest anxiety level had the least mean score. In a study designed to investigate the relationship between test anxiety and academic achievement among undergraduate nursing students, Dawood, Ghadeer, Mitsu, Almutary and Alenezi (2016) found that there was a negative none statistically significant relationship between test anxiety and undergraduate nursing students.Grade point average. In another study conducted to Investigate the Relationship among high School senior Students' test anxiety, academic performance and point of university entrance examination; Karatas, Alci and Aydin (2013) found that there was no significant relationship between test anxiety and grade point average for both female and male students. Similar findings have been reported elsewhere Cheraghian, Fereydouni, Barazpardijani and Bavarsad (2008; Ndirangu, Muola, Kithuka and Nassiuma, 2008;(Kavakci Semiz, Kartal, Dikici and Kugu, 2014).

Gender factor has been an interesting issue in test anxiety research. Several studies have found that female students have higher levels of test anxiety than male students. Cassady and Johnson (2002) for instance found that female students had higher levels of emotionality than males as well as higher levels of cognitive of test anxiety than males. They further found that despite the heightened level of emotionality and cognitive test anxiety reported by females, a repeated measure of analysis of variance revealed no gender differences in course examination performance across the three examinations the students were exposed to. Chapell, etal. (2005), using a large sample of undergraduate and graduate 
students found that female undergraduate student had higher test anxiety than male undergraduates and female graduate students had higher test anxiety than male graduate students. It was further revealed from the same study that despite the females higher test anxiety, the female undergraduates also had significantly higher grade point average than male undergraduate and female graduate students had higher grade point average than male graduate students. Alemu and Feyssa (2020) on the relationship between test anxiety and academic achievement of grade ten students of Shirka Woreda, found that female students had significantly higher test anxiety score than the male students. Apart from the above studies, other researchers have reported contrary findings. In a study of gender differential in anxiety, Fiore (2003) found that there was no overall significant gender disparity in test anxiety. Similarly, Oludipe (2009) found that there was no significant difference between test anxiety levels of male and female physics students. From the above review, it is evident that literature on test anxiety is inconclusive. There is need therefore to provide more empirical evidence to further help explain test anxiety phenomenon in higher institution students' cumulative grade point average (CGPA) which is the summary of the students' performances throughout their stay in the institution.

\subsection{Statement of Problem}

Test anxiety is unfavourable reactions students manifest during testing situations. While acceptable amount of test anxiety is required for students to do well in academic, it is pertinent to know that an elevated level of test anxiety has negative consequences on students' academic performance. Test anxiety leads to low self-esteem, irrelevant thoughts, inability to concentrate and process reading materials, thus leading to underachievement among higher institution students. Some of the causes of examination malpractice, repeating courses of study and withdrawing from academic programmes in higher institutions may be attributed to the detrimental effects of test anxiety. Some of these students end up managing themselves through unhealthy approaches, such as being addicted to hard drugs and alcohol. Early intervention by way of research is of paramount importance.

Most studies on test anxiety were conducted in foreign countries. There is paucity of research on relating test anxiety to higher institution students' cumulative grade point average in the country (Nigeria). Indeed, such local empirical evidence is not available in college of education, Agbor, Nigeria. Besides, gender differential in test anxiety and academic performance have been investigated by many researches. The conflicting results in those studies indicate that more studies from different environmental settings are needed to throw more light in these areas. In view of the above, this study sought to provide answers to; What is the relationship between students' test anxiety scores and their final year cumulative grade point average, Is there gender differential in test anxiety scores and academic performance of the students? Empirical evidence in these areas will aid the institution's authority, lecturers, parents and government to make appropriate decisions with a view to helping students manage or eradicate test anxiety problems.

\subsection{Purpose of the Study}

\subsubsection{Specifically, the Purpose of This Study Was to}

- Examine the relationship between students' test anxiety scores and their final year cumulative grade point average (CGPA).

- Determine whether there is significant difference between the male and female undergraduate students' test anxiety scores.

- Establish whether there is significant difference between male and female undergraduate students' academic performance.

\subsubsection{Hypotheses}

The following hypotheses were formulated and tested at 0.05 level of significance

- There is no significant relationship between students' test anxiety scores and their final year cumulative grade point average.

- There is no significant difference between the test anxiety scores of male and female undergraduate students.

- There is no significant difference in the academic performance (CGPA) of male and female undergraduate students.

\section{Method}

\subsection{Research Design}

The study employed ex-post facto and correlational designs. It is ex-post facto because there was no manipulation of variables as the variables had already occurred. It is correlation, for the fact that students' test anxiety scores were correlated with their cumulative grade point average (CGPA).

\subsection{Population of the Study}

The population for this study comprised 350 final year undergraduate students of 2019/2020 academic session of college of education, Agbor.

\subsection{Sample}

In this study, availability sampling method was applied. Hence a sample of 247 students who were available after a general education course examination participated in the study. These students were equally those who filled the 
questionnaires correctly out of the initial 260 questionnaires that were administered. This sample consisted of 119 male undergraduate students and 128 female undergraduate students. They had average age of 27years.

\subsection{Research Instruments}

Two instruments were used in this study. These are test anxiety scale (TAS) developed by Sarason (1978) and the Students' Academic Records. The researchers adapted the test anxiety scale for use in this study. The first section (A) comprises demographic information while Section B consists of 37 items in which respondents were to respond in terms of 'True' or 'False' as regards their test anxiety status. The test anxiety scale was presented to 40 year three undergraduate students of the college for the purpose of validation. In order to establish the construct validity and internal consistency reliability of the instrument, a Cronbach's coefficient alpha was applied, which yielded an estimate of 0.78. Sarason (1978), using test-rest method reported a coefficient of 0.80 for interval of several weeks. The second instrument was the academic record of the students that contained the cumulative grade point average (CGPA). The cumulative grade point average reflected all the results of the students right from the first year to the final year. This record was domiciled in the degree office of the college.

\subsection{Administration of Instrument and Data Collection}

The test anxiety scale which consisted of 37 items with two response categories of true or false was administered to 260 final year students after they had finished one of their education examinations. A score of one (1) was assigned to a response that reflected test anxiety whereas zero $(0)$ was assigned to a response that reflected no anxiety. By this means, the students' test anxiety scores were collected. From the administered 260 copies of the test anxiety scale, 13 copies were not properly filled or completed, thus leading to 247 students that appropriately completed the scale. Hence analysis of data was based on the data collected from the 247 students. The students' cumulative grade points average reflecting all the relevant courses done by the students were collected from the degree office of the college a few months after the student's last examination in the college. This period was necessary to allow the college authority compute the cumulative grade points average of the students.

\subsection{Data Analysis}

The collected data were coded and analyzed using regression and t-test statistics. The stated hypotheses were tested at 0.05 level of significance.

\section{Results and Discussion}

- $\quad$ Hypothesis one: It was stated that there would be no significant relationship between students' test anxiety scores and their final year cumulative grade point average. Tables 1 and 2 show the summary of the analysis.

\begin{tabular}{|c|c|c|c|c|c|}
\hline Model & Sum of Square & DF & $\begin{array}{c}\text { Mean } \\
\text { Square }\end{array}$ & F & Significance \\
\hline $\begin{array}{c}\text { Regression } \\
\text { Residual }\end{array}$ & 3.874 & 1 & 3.874 & 7.544 & .006 \\
Total & 125.808 & 246 & & & \\
\hline \\
Table 1: ANOVA of Regression for the Relationship between Students' Test Anxiety \\
Scores and Their Final Year CGPA \\
$R=-0.173 ;$ R Square = 0.030
\end{tabular}

\begin{tabular}{|c|c|c|c|}
\hline Model & $\begin{array}{c}\text { Standardized Coefficient } \\
\text { (Beta) }\end{array}$ & T & Significance \\
\hline $\begin{array}{c}\text { Constant } \\
\text { TAS }\end{array}$ & -0.173 & 21.555 & 0.000 \\
& & -2.747 & 0.006 \\
\hline
\end{tabular}

Table 2: Regression Coefficients

Table 1 shows that there was significant relationship between students' test anxiety scores and their cumulative grade point average as F1, 247=7.544; $\mathrm{P}<0.05$. As indicated in table 2 , test anxiety has a predicted strength of -0.173 as shown by the Beta value. The analysis further shows that test anxiety has significantly accounted for $3 \%$ of the total variance in the students' performance in the criterion variable $\left(\mathrm{R}^{2}=0.30\right.$.) The finding implies that test anxiety has a significant negative influence on students' learning in the institution. That is as test anxiety increased, academic performance or cumulative grade points average of students decreased. This finding may be as a result of the fact that test over anxious students tend to find it more problematic in avoiding distractions and spend more time in shifting their attention from one task to the other. Such distractions will lead to inability of students to effectively concentrate attention on learning materials, thus leading to underachievement. This finding is in agreement with Chapell etal (2005), Zeidner (2007), Eysenck (2009), Afolayan, etal (2013) and Alemu \& Feyssa (2020) who found significant negative relationship between test anxiety and academic performance of study. However, this finding contradicts that of Awolobi and Etuk-Iren (2014) and Dawood, etal (2016) who found no significant relationship between test anxiety scores and academic achievement of students in their studies. 
- Hypothesis two: It was hypothesized that there would be no significant difference between the test anxiety scores of male and female undergraduate students. The results of the analysis as regards this hypothesis are presented in table 3.

\begin{tabular}{|c|c|c|c|c|c|c|c|}
\hline Gender & No. & Mean & SD & DF & T. Cal. & P. Value & Remark \\
\hline Male & 119 & 21.8403 & 5.92893 & & & & Not \\
Female & 128 & 21.000 & 6.43198 & & & & \\
& & & & & & & Significant \\
\hline
\end{tabular}

Table 3: T-Test Analysis of Anxiety Test Scores of Male and Female Undergraduate Students

Thet-test comparison shows that there was no statistical significant difference between the test anxiety scores of male and female undergraduate students ( $\mathrm{t}$-calculated $=1.065, \mathrm{df}=245 ; \mathrm{P}>0.05)$. Though there was a slight difference between the anxiety scores of both genders, with the males having a higher mean test anxiety score of 21.8403 while the females had a mean anxiety score of 21.000. This finding implies that gender has no significant influence on undergraduate students test anxiety scores. There has been increasing awareness of gender equality in almost all aspects of life in the country (Nigeria) through social media. This might be the reason why both genders did not significantly differ in their reactions to testing situations. This finding tends to suggest that if both male and female undergraduate students are given equal and appropriate orientation and training, the negative consequences of test anxiety on academic performance of both genders may be at vanishing point. This finding in this study is in consonance with Oludipe (2009) and Fiore (2003) who found no significant difference in the test anxiety scores of male and female students. This present finding is not in harmony with that of Chapell, etal (2005) and Alemu \& Feyssa (2020) who reported gender differential in test anxiety scores in their studies.

- Hypothesis Three: It was stipulated that there would be no significant difference in the cumulative grade point average of male and female undergraduate students. Table 4 shows the results of the analysis.

\begin{tabular}{|c|c|c|c|c|c|c|c|}
\hline Gender & No. & Mean & SD & DF & T. Cal. & P. Value & Remark \\
\hline Male & 119 & 2.9024 & 0.73069 & & & & Not \\
\hline Female & 128 & 2.9336 & 0.72482 & 245 & 0.337 & 0.806 & Significant \\
\hline
\end{tabular}

Table 4: T-Test Analysis of the Cumulative Grade Points Average of Male and Female Undergraduate Students

From table 4, it is evident that there was no significant difference in the cumulative grade points average of male and female undergraduate students in the institution ( $\mathrm{t}$-calculated $=0.337 ; \mathrm{Df}=245 ; \mathrm{P}>0.05$ ). This implies that gender has no significant influence on how the students learn in the institution. This finding could be as a result of lack of significant difference in the test anxiety scores of male and female undergraduate students. The present finding is in agreement with Owolabi and Etuk-Iren (2014) who found that gender had no significant influence on the academic performance of the students they investigated in their study. However, our finding in this aspect contradicts that of Chapell etal (2005) who investigated test anxiety and academic performance in undergraduate and graduate students and found that female undergraduate and graduate students respectively had significant higher GPA than male undergraduate and graduate students.

\section{Conclusion and Recommendations}

Analysis of data in this study has shown that there was a significant negative relationship between test anxiety and undergraduate students' academic performance in the college. The study has also revealed that there was no significant difference in the test anxiety scores of male and female undergraduate students. Further analysis has revealed that there was no significant difference between the academic performance (CGPA) of male and female undergraduate students.

Based on the above findings, it is therefore recommended as follows;

- There is the need for the college authority to create test anxiety awareness before each examination to guide the students against the danger of heightens level of test anxiety.

- Lecturers should take note of the deleterious effect of elevated level of test anxiety and make sure that classroom environment is less stressful. They should therefore aim at providing learning atmosphere that offers tolerable level of anxiety that stimulates the students to learn well and keep on learning.

- Formative tests and assignments should be well planned in advance in order to reduce tension and trepidation. Students can be directed to where they can locate reading materials necessary for assignments and preparation for tests.

- There is need for the students to be taught test preparation and test taking skills. This will help them develop confidence during examination.

- Students should be encouraged to visit the institution counseling centre. Such counseling on test anxiety should be offered to meet the needs of all the students irrespective of students' gender. 
- Lecturers, school counselors, parents and others who are concerned about the academic performance of higher institution students should always encourage the students to focus attention on the positive thought of having good grades and the attending rewards. This will act as impetus to help them study hard and prepare well for examinations.

- The institution's library should be well furnished with relevant reading materials. The internet facilities should be activated and expanded to accommodate appreciable number of students at a time. This measure will help to reduce stress on the part of the students in locating reference materials.

Furthermore, since there are many factors influencing higher institution students' academic performance, further studies can focus on the interaction effects of test anxiety and some or any of these factors on students' academic achievement.

\section{References}

i. Alemu; B.M. \& Feyssa, T. (2020). The relationship between test anxiety and academic achievement of grade ten students of Shirka Woveda, Oromia Regional State, Ethiopia. African Educational Research Journal; 8(3), 540550.

ii. Afolayan, J. A; Donald, B; Onasoga, O; Babafemi, A. \& Juan, A. (2013). Relationship between anxiety and academic performance of nursing students. Niger Delta University, Bayelsa State, Nigeria. Advances in Applied Science Research, 4(5), 25-33.

iii. Bandolos, D. l.; Yates, K \& Thomdike, C.T. (1995). Effects of math self concept, perceived self-efficacy and attributors for failure and success on test anxiety. Journal of educational psychology, 87(4); 611-623.

iv. Barlow, D.H. (2002). Anxiety and its disorders. New York: Guilford Press

v. Cassady, J. C. \& Johnson, R.E. (2002) Cognitive test anxiety and academic performance. Contemporary Educational Psychology, 27, 270-295.

vi. Chapell, M. S.; Blanding, Z.B.; Silverstein, M.E.; Takahashi, M. Newman, B, Gubi, A. \& Micann, N. (2005). Test anxiety and academic performance in undergraduate and graduate students. Journal of Educational Psychology; 97(2), 268-274.

vii. Cheraghian, B; Fereydouni, M; Barazpardijani, S. \& Bavarsad, N. (2008). Test anxiety and its relationship with academic performance among nursing students. Journal Knowledge Health. 3(4), 25-29.

viii. Dawood, E; Ghadeer, H. A.; Mitsu, R; Almutary, N. \& Alenezi, B. (2016). Relationship between test anxiety and academic achievement among undergraduate nursing students. Journal of Education and Practice; 7(2); 57-65.

ix. DordiNejad, F. G; Hakim, H; Ashouri, M., Deghighi, M. S. \& Bahrami, (2011). On the relationship between test anxiety and academic performance. Social and Behavioural Sciences. 15(2011). 3774-3778.

x. Eysenck, M.W. (2009). The effect of anxiety on academic achievement of students. Retrieved from http//www.sciencedaily.com/release/2009/06090623090713.htm; 1507-2012.

xi. Fiore, M.M. (2003). Gender differences in test anxiety. Thesis submitted to the College of Human Resources and Education at West Virginia University in partial fulfillment of the requirements for the degree of Master of Arts in Educational Psychology.

xii. Kavakci, O; Semiz, M; Kartal, A; Dikici; A. \& and Kugu, N. (2014). Test anxiety prevalence and related variables in the students who are going to take the university entrance examination, Dusunen Adem. The Journal of Psychiatry and Neurological Sciences. 27 (4) 301-307.

xiii. Karatas, H; Alci, B. \& Aydin, H. (2013). Correlation among high school senior students' test anxiety, academic performance and points of university entrance exam. Educational Research and Reviews 8(3); 919-922

xiv. Ndirangu, G. W; Muola, J. M. Kithuka, M.R. \& Nassiuma, D. K. (2008). An investigation of the relationship between test anxiety and academic performance in secondary schools in Nyeri, District, Kenya. Global Journal of Educaitonal Research; 7 (1\&2).

xv. Nedeem, M; Ali, A. Magbool, S. \& Zaidi, S.U. (2012) Impact of anxiety on the academic achievement of students having different mental abilities at university level in Bahawalpur (Southern Punjab) Pakistan International Journal of Educational Sciences 4(3); 519-528.

xvi. Oludipe, B. D. (2009). Influence of test anxiety on performance levels on numerical tasks of secondary school physics students; Academic Leadership Online Journal 7(4).

xvii. Oluoch, J.N; Aloka, J.O. \& Odondo, B.C. (2018).Test anxiety, beliefs as predictor of students' achievement in chemistry in public secondary schools in Kenya. International Journal of Psychology and Behavioural Sciences, 8(4); 70-76.

xviii. Owolabi, J. \& Etuk-Iren, O.A. (2014). Effect of gender, age and mathematics anxiety on college students' achievement in algebra. American Journal of Educational Research; 2(7), 474-476.

xix. Passer, M; Smith, R; Holt, N; Bremner, A; Sutherland, E. \& Vlick, M. (2009), Psychology: The science of mind and behaviour. New York: McGraw - Hill Companies, Inc.

xx. Ramalingan, P. (2006). Dictionary of Psychology. New Delhi: Academic Publishers.

xxi. Seligman, M.E.P; Walker, F.F. \& Rosenhan, D.L. (2008). Abnormal Psychology. (4thed). New York: W.W. Norton \& Company, Inc.

xxii. Sarason, I.G. (1978). The test anxiety scale: Concept and Research. In C.D. Spielberger and I. G. Sarason (Eds). Stress and Anxiety (5). Washington D.C; Hemisphere Publishing Corp.

xxiii. Sarason, I.G. (1984). Stress, anxiety and Cognitive interference: Reactions to test. Journal of Personality and Social Psychology, 46, 929-938. 
xxiv. Williams, J.E. (1991) Modeling test anxiety, self-concept and high school students' academic achievement. Journal of Research and Development in Education.

xxv. Zahrakar, K. (2008). Stress Consultant (Isted.) Tehram: Bal. University Publication.

xxvi. Zeidner, M. (2007). Test anxiety in educational contexts: Concepts, findings and future directions. In P. A. Schut, \& R. Pekrun (Eds.), Emotion and education (PP. 165-184). San Diego, CA: Elsevier Inc. 